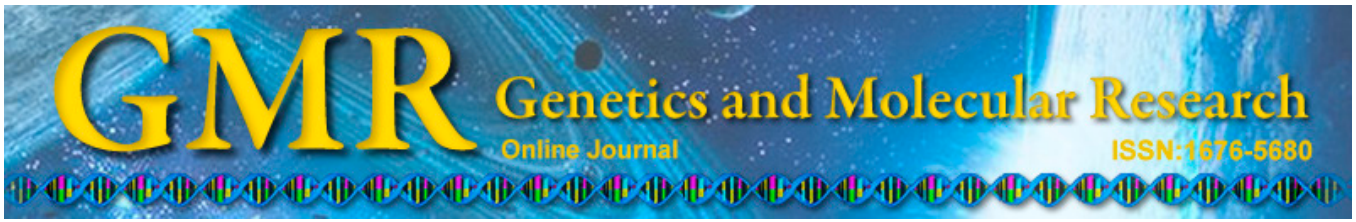

\title{
Verification and characterization of chromosome duplication in haploid maize
}

\author{
E.G. de Oliveira Couto ${ }^{1}$, E.V. Resende Von Pinho ${ }^{1}$, R.G. Von Pinho ${ }^{1}$, \\ A.D. Veiga ${ }^{2}$, M.R. de Carvalho ${ }^{1}$, F. de Oliveira Bustamante ${ }^{3}$ and \\ M.S. Nascimento ${ }^{1}$ \\ ${ }^{1}$ Departamento de Agricultura, Universidade Federal de Lavras, \\ Lavras, MG, Brasil \\ ${ }^{2}$ Embrapa Cerrados, Planaltina, DF, Brasil \\ ${ }^{3}$ Departamentode Biologia, Universidade Federal de Lavras, \\ Lavras, MG, Brasil \\ Corresponding author: E.G. de Oliveira Couto \\ E-mail: evellyn.couto@yahoo.com.br
}

Genet. Mol. Res. 14 (2): 6999-7007 (2015)

Received November 18, 2014

Accepted February 23, 2015

Published June 26, 2015

DOI http://dx.doi.org/10.4238/2015.June.26.9

ABSTRACT. Doubled haploid technology has been used by various
private companies. However, information regarding chromosome
duplication methodologies, particularly those concerning techniques
used to identify duplication in cells, is limited. Thus, we analyzed
and characterized artificially doubled haploids using microsatellites
molecular markers, pollen viability, and flow cytometry techniques.
Evaluated material was obtained using two different chromosome
duplication protocols in maize seeds considered haploids, resulting
from the cross between the haploid inducer line KEMS and 4 hybrids
(GNS 3225, GNS 3032 , GNS 3264, and DKB 393). Fourteen days
after duplication, plant samples were collected and assessed by flow
cytometry. Further, the plants were transplanted to a field, and samples
were collected for DNA analyses using microsatellite markers. The
tassels were collected during anthesis for pollen viability analyses.
Haploid, diploid, and mixoploid individuals were detected using 
flow cytometry, demonstrating that this technique was efficient for identifying doubled haploids. The microsatellites markers were also efficient for confirming the ploidies preselected by flow cytometry and for identifying homozygous individuals. Pollen viability showed a significant difference between the evaluated ploidies when the Alexander and propionic-carmin stains were used. The viability rates between the plodies analyzed show potential for fertilization.

Key words: Doubled haploids; Flow cytometry; Microsatellite markers; Pollen viability; Zea mays

\section{INTRODUCTION}

The success of a breeding program in the production of commercial maize hybrids involves the attainment of endogamic lines (Paterniani and Campos, 1999). In order to obtain hybrid maize, it is initially necessary to cross two or more homozygous lines. Various elite line attainment technologies have been employed for this purpose, such as the successive selffertilization processes, recurrent selection, backcrossing, and, most recently, haploid duplication technology or doubled haploids (Chase, 1952).

To produce doubled haploid lines in maize, it is initially necessary to obtain haploid seeds, which can be induced by haploid inducer lines (Kermicle, 1973; Röber et al., 2005; Rotarenco et al., 2010) and then further selected and subjected to an artificial duplication protocol.

Various authors have conducted chromosome duplication in haploid seeds of maize, obtaining variable percentages of duplicated seeds (Deimling et al., 1997; Chalyk, 2000; Battistelli et al., 2013). However, information regarding the techniques used to confirm and identify chromosome duplications remains limited.

In doubled haploid technology, flow cytometry is used because it is easy and timeefficient in the preparation of samples and attainment of results (Loureiro and Santos, 2004). Because flow cytometry can be used to directly evaluate DNA content and indirectly determine the ploidy level, this technique allows for the analyses of haploid induction as well as the chromosome duplication (Dang et al., 2012; Battistelli et al., 2013; Couto et al., 2013).

Another tool used to identify haploids and doubled haploids are microsatellite molecular markers. Because they are codominant and stable, these markers allow for the separation of homozygous and heterozygous individuals, enabling the study of genetic inheritance and gene introgression (Belicuas et al., 2007, Li et al., 2009; Battistelli et al., 2013; Couto et al., 2013).

Pollen viability studies are also important in studies involving doubled haploids, as self-fertilization processes are conducted in the field to attain seeds from doubled haploid lines after chromosome duplication.

Thus, the aim of this study was to analyze and characterize artificially doubled haploid maize plants using microsatellite molecular markers, pollen viability, and flow cytometry techniques.

\section{MATERIAL AND METHODS}

\section{Evaluated germplasm}

Seeds originating from a cross between the gymnogenetic haploid inducer line KEMS 
(Shatskaya et al., 1994), and four maize hybrids (DKB 393, GNS 3225, GNS 3264, and GNS 3032) with a white embryo and purple endosperm were selected, classified as probable haploids (Chase and Nanda, 1965), and subject to one of the two chromosome duplication protocols (Protocols 1 and 2) (Couto et al., unpublished results). Plants that survived the chromosome duplication in both protocols were evaluated.

\section{Flow cytometry}

The amount of DNA was estimated from the leaf tissue of the parents and from the descendants originating from the crosses that survived the chromosome duplication for both protocols (Couto et al., unpublished results) 14 days after colchicine treatment. The plants were analyzed in order to identify the ploidies resulting from artificial duplication.

For each sample, approximately $20-30 \mathrm{mg}$ of young leaves of the evaluated individual was used. Vicia faba, containing $26.9 \mathrm{pg} / 2 \mathrm{C}$ amount of DNA, was used as an external reference standard. The samples were ground on a Petri dish containing $1 \mathrm{~mL}$ chilled LB01 buffer to obtain the nuclear suspension (Doležel, 1997), to which $2.5 \mu \mathrm{L}$ RNase was added and stained with $25 \mu \mathrm{L}$ propidium iodide $(1 \mathrm{mg} / \mathrm{mL})$. For each sample, a minimum of 10,000 nuclei were analyzed. Histograms were obtained using the FacsCalibur (BD Biosciences, Franklin Lakes, NJ, USA) flow cytometer with the Cell Quest (BD Biosciences) program, and analyzed using the WinMDI 2.8 software 2009.

\section{Microsatellite markers}

For the DNA analyses using simple sequence repeat (SSR) markers, leaf samples of the parents, and from haploid, haploid/diploid or doubled haploid, and diploid individuals that had been previously identified using flow cytometry, were collected in the field.

Extraction was conducted according to Doyle and Doyle (1987). The DNA was quantified using a GE Nanovue spectrophotometer (GE Healthcare, Little Chalfont, UK).

For this study, 80 random pairs of SSR primer were used; these primers have been used in previous studies involving maize culture. Gels were stained using silver nitrate. Two primers that were considered to be polymorphic (BNLG238 and 1233) were used to detect homozygous individuals and possible gymnogenetic haploids or doubled haploids were identified using flow cytometry.

The amplification products were separated by $10 \%$ polyacrylamide gel electrophoresis at $110 \mathrm{~V}$ for $90 \mathrm{~min}$.

\section{Pollen viability}

Pollen viability analysis was conducted in haploid, diploid, and mixoploid individuals originating from Protocol 1 of chromosome duplication (Couto et al., unpublished results), previously detected using flow cytometry. Haploid/diploid or doubled haploid and diploid/ tetraploid pollen was collected from mixoploid individuals. Pollen grain collection was conducted in the field during anthesis at 9 a.m. Pollen grains were fixed in Carnoy's solution (ethyl alcohol: glacial acetic acid/3:1) and stored at a temperature of $-20^{\circ} \mathrm{C}$, until slide production.

Pollen grain viability was estimated based on their coloring capacity using two colorimetric tests, including propionic-carmin and Alexander's stains. For propionic-carmin stain- 
ing, pollen grains were considered to be viable when they were red in color. Those that were unstained were considered to be unviable. Using Alexander's stain, unviable pollen grains stained green, while the viable grains stained purple.

Ten slides were evaluated by ploidy and 100 pollen grains by slide, for each stain used. Photomicrographs of the pollen grains were obtained using a bright field microscope (Zeiss, Jena, Germany), and images were captured using an FDX35 camera attached to a microcomputer.

Based on pollen viability data, variance analysis was conducted followed by the Scott and Knott test $(\mathrm{P}<0.05)$, using two approaches: considering the variations between genotypes and between stains within the genotypes.

\section{RESULTS}

\section{Flow cytometry for identifying doubled plants}

Haploid, diploid, and mixoploid plants were verified by flow cytometry analyses for both protocols (Table 1).

\begin{tabular}{lcr} 
Table 1. Ploidy percentages detected in plants examined using the protocols for chromosome duplication. \\
\hline Detected ploidies & \multicolumn{2}{c}{ Plant percentages } \\
\cline { 2 - 3 } & Protocol 1 & Protocol 2 \\
\hline Diploids & 10.49 & 13.65 \\
Haploids & 33.64 & 12.06 \\
Mixoploids & 55.86 & 74.28 \\
\hline
\end{tabular}

All ploidies detected were characterized by comparing the peaks of the doubled plants with the peaks of the diploid parent hybrids (GNS 3032, GNS 3225, GNS 3264, and DKB 393), that were not doubled, and also with the external standard peak used, Vicia faba on the histograms (Figure 1A).

Within mixoploid plants, in protocol 1, 41.97\% haploid/diploid, $13.58 \%$ diploid/tetraploid, and $0.3 \%$ diploid/octoploid plants were observed. In protocol 2 , within the mixoploid plants, $20.63 \%$ haploid/diploid, 5.39\% haploid/tetraploid, 1.58\% haploid/octoploid, $6.66 \%$ diploid/tetraploid, and $8.57 \%$ diploid/octoploid plants were observed.

The histograms of haploids and diploids revealed which plants that had not been doubled (Figure 1B and C). The plants that presented more than one ploidy in the histograms, or mixoploids, (having more than $1 \mathrm{G} 1$ peak), were doubled by colchicine treatment (Figure 1DH). Doubled haploids showed ploidies of the haploid/diploid type (Figure 1D).

\section{SSR molecular markers for characterizing doubled haploids}

The polymorphic primers allowed for the distinction of homozygous, haploid or doubled haploid, diploid, and heterozygous individuals (Figures 2 and 3). It was possible to confirm the gymnogenetic inheritance of the haploid inducer line KEMS through molecular analyses, as the haploids or doubled haploids, because of their homozygous nature, showed only one band in the gel, which originated from the hybrid genitor used as the female parent. 
This result confirms the results of flow cytometry. Only in a further stage, when the homogeneity of the doubled seeds is analyzed, the doubled haploids can be confirmed.
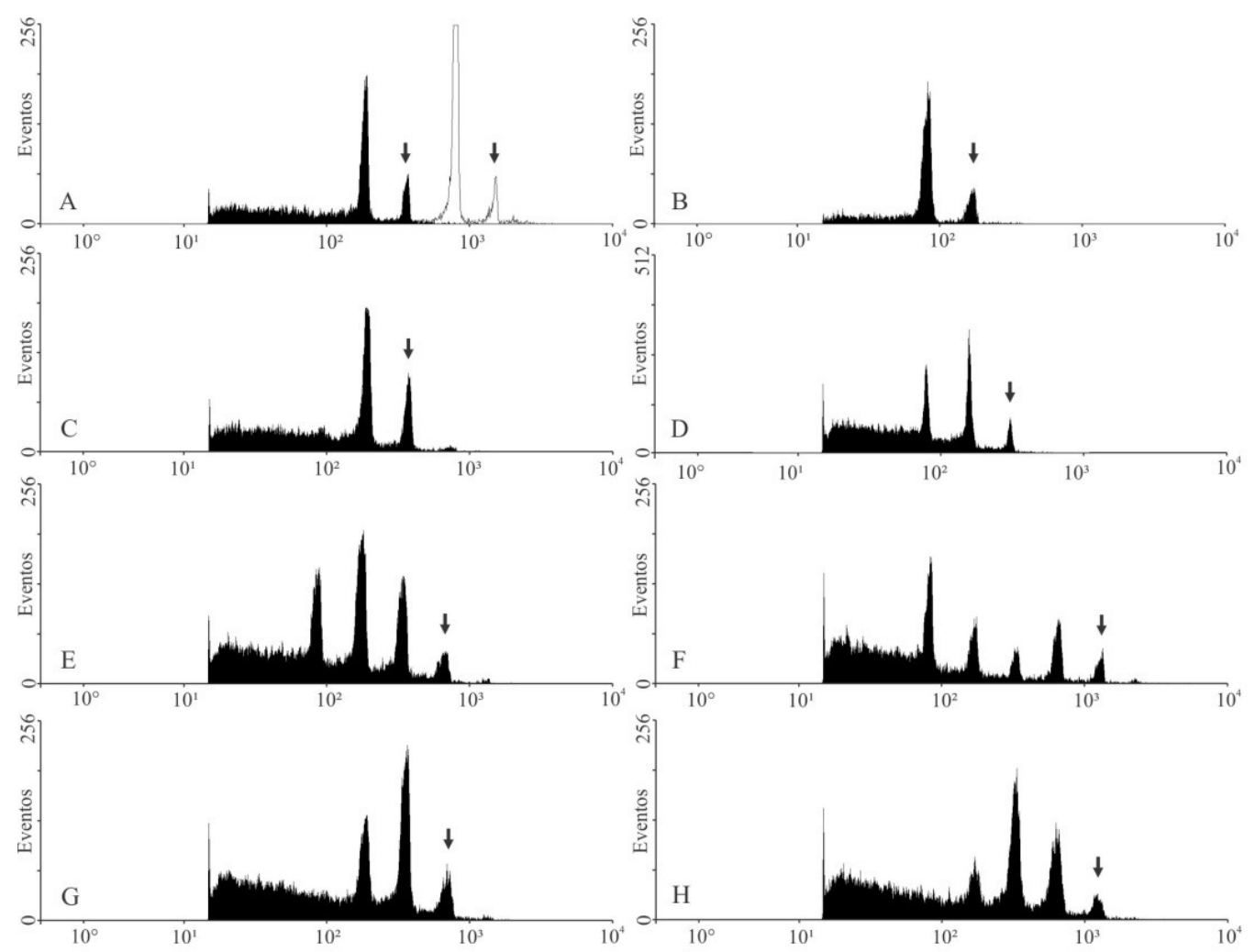

Figure 1. Histograms of the ploidies detected by flow cytometry in maize plants. Parent GNS 3225 with external standard Vicia faba (A). Non-doubled haploid plant (B). Non-doubled diploid plant (C). Mixoploids: haploid/ diploid plant (D). Haploid/tetraploid plant (E). Haploid/octoploid plant (F). Diploid/tetraploid plant (G). Diploid/ octoploid plant $(\mathbf{H})$. Vertical axis $=$ number of nuclei read; horizontal axis = relative fluorescence intensity. Arrow evidence $\mathrm{G}_{2}$ phase of the cell nuclei. Remaining peaks are $\mathrm{G}_{1}$ phase.

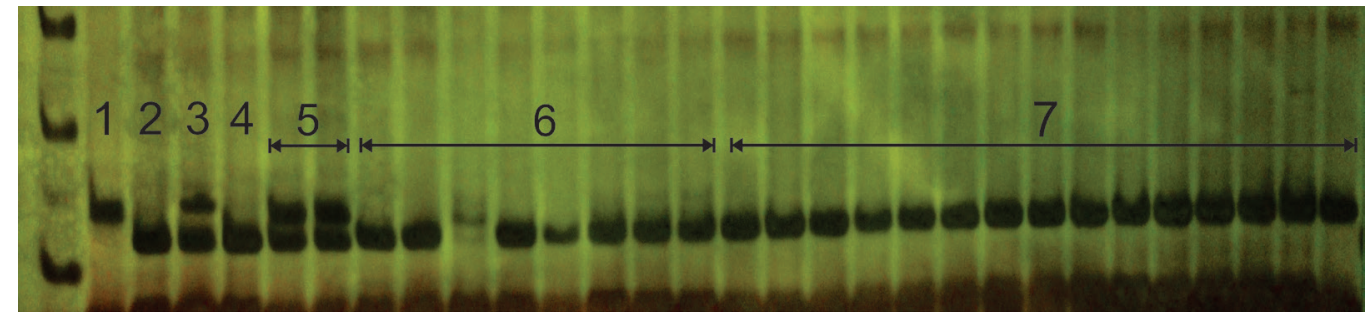

Figure 2. Electrophoretic standard of the products of the polymorphic primer amplification BNLG 238. 1) Parent KEMS. 2) Parent GNS 3032. 3 and 5) Non-doubled diploids. 4 and 6) Non-doubled haploids. 7) Haploids/diploids, or doubled haploids. 


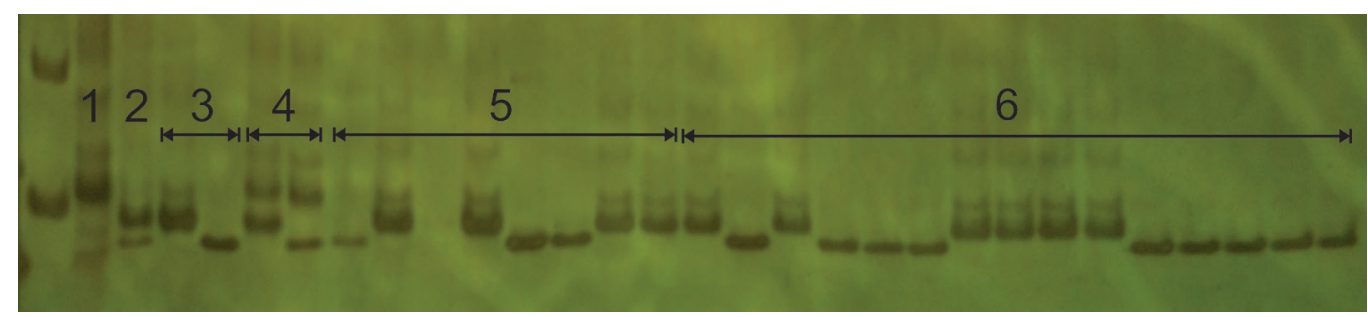

Figure 3. Electrophoretic standard of the polymorphic primer amplification products BNLG 1233. 1) Parent KEMS. 2) Parent GNS 3032. 3 and 5) Non-doubled haploids. 4) Non-doubled diploids. 6) Haploids/diploids, or doubled haploids.

\section{Pollen viability}

We observed a significant difference between the ploidies evaluated for the pollen viability rates when the propionic-carmin and Alexander's stains were used (Table 2 and Figure 4). Diploid/tetraploid individuals presented the highest viability rates, followed by haploid individuals. Diploid and doubled-haploid individuals presented the lowest rates. There was no significant difference between the stains used.

Table 2. Colorimetric assays in maize individuals subject to chromosome duplication.

\begin{tabular}{lcc}
\hline Individuals & Propionic carmin stain & Alexander's stain \\
\hline Haploid & $8.42^{\mathrm{Ab}}$ & $4.02^{\mathrm{Ab}}$ \\
Doubled haploid & $0.62^{\mathrm{Ac}}$ & $0.4^{\mathrm{Ac}}$ \\
Diploid & $0.55^{\mathrm{Ac}}$ & $0.51^{\mathrm{Ac}}$ \\
Diploide/tetraploid & $86.45^{\mathrm{Aa}}$ & $84.07^{\mathrm{Aa}}$ \\
\hline
\end{tabular}

Distinct lower cases in the column: significance difference by the Scott and Knott test $(\mathrm{P}<0.05)$. Distinct upper cases in the line: significant difference by the Scott and Knott test $(\mathrm{P}<0.05)$.
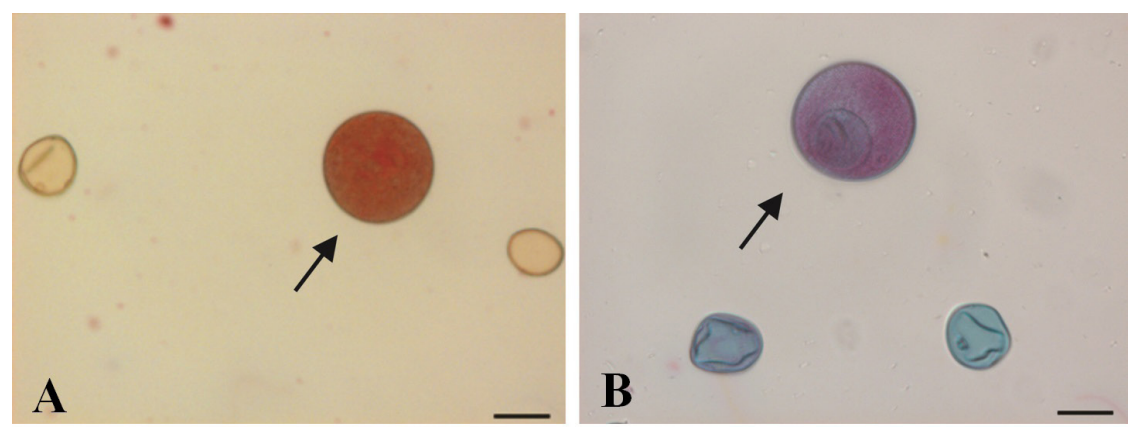

Figure 4. Pollen grains of maize plants subject to chromosome duplication. A. Haploid stained with Alexander's stain. B. Diploid/tetraploid stained with propionic-carmin stain. Arrow indicates viable pollen grains. $\mathrm{Bar}=5 \mu \mathrm{M}$.

\section{DISCUSSION}

Flow cytometry is advantageous in experiments involving chromosome duplication (Choe et al., 2012; Dang et al., 2012; Battistelli et al., 2013; Couto et al., 2013), as the sample 
is not degraded because only a piece of the leaf is sufficient for the analyses and little time is required for cytometry measurements (Loureiro and Santos, 2004). In this study, we analyzed all doubled plants in less than one week.

We verified that both chromosome duplication protocols were efficient, as they presented high mixoploid percentages, including $55.86 \%$ for protocol 1 and $74.28 \%$ for protocol 2. Moreover, the protocols were efficient for determining the percentage of doubled-haploid plants (haploid/diploid) obtained, with values of 41.97 and $20.63 \%$ for protocols 1 and 2, respectively.

Protocol 1 resulted in a value of haploids and doubled haploids (33.64 and 41.97\%, respectively), which was higher than values obtained using protocol 2 (12.06 and 20.63\%, respectively). This is mainly because the seed sampling was initially selected based on the R-navajo marker. As the seeds were divided for chromosome duplication protocols based on visual inspection, protocol 1 gave more haploid seeds than did protocol 2 . Thus, a higher percentage of haploid and doubled-haploid plants was observed for protocol 1.

However, a higher percentage of mixoploids $(74.28 \%$ ) was observed for protocol 2 compared to protocol 1 (55.86\%), as well as higher ploidy values between the mixoploids in protocol 2 ( 5 classes) than in protocol 1 ( 3 classes). This is likely because of the higher concentration of antimitotic agent used in protocol 2, although it was used for a shorter amount of time (Couto et al., unpublished results).

Battistelli et al. (2013) used a protocol proposed by Deimling et al. (1997) and detected doubled haploids using flow cytometry. The authors observed the levels of ploidies, including haploids, haploids/diploids, diploids, and diploids/tetraploids. In the present study, protocol 2 presented variation values in the ploidies between the mixoploids that were higher than those in the protocol proposed by Deimling et al. (1997).

The microsatellite markers, because of their codominant nature, allowed for easy visualization and identification of homozygous individuals. Thus, it was possible to distinguish the diploids, which are heterozygous, from the haploids and doubled haploids, which are homozygous. Differentiation between these two is possible in the field, mainly because of the absence of pollen and low vigor of the haploid plants.

The results obtained in the present study agree with those of previous studies, indicating that the markers are reliable. Belicuas et al. (2007) and Couto et al. (2013) used microsatellite markers to detect androgenetic haploids in maize and observed only one band in the haploid individual. Battistelli et al. (2013) used SSR to confirm whether the plants that presented peaks for haploid cells in the histograms generated by flow cytometry were truly haploids.

Figure 3 shows that some haploid/diploid plants had brighter bands, leading to their classification as diploid plants. However, both primers were used in the genotyping, and according to the band amplification of the different genotypes, the BNLG 1233 primer can be used in other studies. Figure 2 shows that these haploid/diploid plants presented strong bands in the gel, confirming the ploidy detected by flow cytometry. Thus, the SSR molecular markers can be used to confirm the gymnogenetic inheritance of the haploid inducer line KEMS as well as to identify maize doubled-haploid plants.

Various studies have examined maize pollen viability (Ferreira et al., 2007; Davide et al. 2009; Balbinot et al., 2011; Feng et al., 2014). However, there have been no experiments examining viability in plants subjected to artificial chromosome duplication.

In the present study, the doubled haploids, considered here as duplicated haploids, presented viability rates lower than those of the haploids that were not duplicated. Moreover, the 
diploid individuals showed rates lower than those of the haploids. Techio et al. (2006) suggested that the differences could be explained by loss of pollen viability, which may vary considerably between individuals of the same species and between samples of the same individual.

Davide et al. (2009) verified the viability of stored maize pollen using in vivo and in vitro tests and obtained values higher than $95 \%$ pollen viability when Alexander's stain was used. This value was independent of the genetic material used, the in vitro germination rate, and the production of seeds per spike. In other studies of maize pollen viability, the authors discuss the loss of pollen viability as the pollen grains are dried (Almeida et al., 2011; Alvim, 2012).

Geiger and Schönleben (2011) found that haploid plants may produce a fertile tassel, but in an excessively small percentage of plants. These authors identified haploid plants producing viable pollen and described the importance of improving this trait, as these haploid plants can be used to produce fertile pollen over the long term.

In the present study, we observed no significant difference between the stains used, indicating good precision in viability evaluations and high reliability of the results. Moreover, the viability rates between the ploidies analyzed indicate the potential to fertilize, which was mainly observed in tetraploid individuals.

\section{ACKNOWLEDGMENTS}

Research supported by Conselho Nacional de Desenvolvimento Científico e Tecnológico (CNPq) and Fundação de Amparo à Pesquisa do Estado de Minas Gerais (FAPEMIG).

\section{REFERENCES}

Almeida C, do Amaral AL, Neto JFB and de Melo Sereno MJC (2011). Conservação e germinação in vitro de pólen de milho (Zea mays subsp. mays). Rev. Bras. Bot. 34: 493-497.

Alvim PO, Von Pinho RG, Von Pinho EVR, Veiga AD, et al. (2012). Meios de cultura para germinação de grãos de pólen de milho. Rev. Agrar. 5: 206-211.

Balbinot A, Delai RM and Werle AJK (2011). Viabilidade do pólen de milho. Rev. Cult. Saber 4: 133-142.

Battistelli GM, Von Pinho RG, Justus A, Couto EGO, et al. (2013). Production and identification of doubled haploids in tropical maize. Genet. Mol. Res. 12: 4230-4242.

Belicuas PR, Gimarães CT, Paiva LV, Duarte JM, et al. (2007). Androgenetic haploids and SSR markers as tools for the development of tropical maize hybrids. Euphytica 156: 95-102.

Chalyk ST (2000). Obtaining fertile pollen in maize maternal haploids. Maize Genet. Newsl. 74: 17-18.

Chase SS (1952). Production of homozygous diploids of maize from monoploids. Agron. J. 44: 263-267.

Chase SS and Nanda DK (1965). Comparison of variability in inbred lines and monoploid-derived lines of maize (Zea mays L.). Crop Sci. 5: 275-276.

Choe EH, Carbonero CH, Mulvaney K, Rayburn AL, et al. (2012). Improving in vivo maize doubled haploid production efficiency through early detection of false positives. Plant Breed. 131: 399-401.

Couto EGO, Davide LMC, Bustamante FO, Von Pinho RG, et al. (2013). Identification of haploid maize by flow cytometry, morphological and molecular markers. Cienc. Agrotec. 37: 25-31.

Dang NC, Munsch M, Aulinger I, Renlai W, et al. (2012). Inducer line generated doubled haploid seeds for combined waxy and opaque 2 grain quality in subtropical maize (Zea mays L.). Euphytica 183: 153-160.

Davide LMC, Pereira RC, Abreu GB, Souza JC, et al. (2009). Viabilidade de pólen de milho em diferentes períodos de armazenamento em baixa temperatura. Rev. Bras. Milho Sorgo 8: 199-206.

Deimling S, Rober F and Geiger HH (1997). Methodik und genetik der in-vivo-Haploideninduktion bei mais. Vorträge für Pflanzenzüchtung 38: 203-224.

Doležel J (1997). Applications of flow cytometry for the study of plants genomes. J. Appl. Genet. 38: 285-302.

Doyle JJ and Doyle JL (1987). A rapid DNA isolation procedure for small quantities of fresh leaf tissue. Phytochem. Bull. 19: 11-15. 
Feng PCC, Qi Y, Chiu T, Stoecker MA, et al. (2014). Improving hybrid seed production in corn with glyphosate-mediated male sterility. Pest Manag. Sci. 70: 212-218.

Ferreira CA, Von Pinho EVR, Alvim PO, Andrade V, et al. (2007). Conservação e determinação da viabilidade de grão de pólen de milho. Rev. Bras. Milho Sorgo 6: 159-173.

Geiger HH and Schönleben M (2011). Incidence of male fertility in haploid elite dent maize germplasm. Maize Genet. Coop. News Lett. 85: 1-10.

Kermicle JL (1973). Androgenesis and the indeterminate gametophyte(ig) mutation: influence of pollen parent on androgenese frequency. Maize Genet. Coop. News Lett. 47: 207-208.

Li L, Xu X, Jin W and Chen S (2009). Morphological and molecular evidences for DNA introgression in haploid induction via a high oil inducer CAUHOI in maize. Planta 30: 367-376.

Loureiro J and Santos C (2004). Aplicação da citometria de fluxo ao estudo do genoma vegetal. Bol. Biotecnol. 77: 18-29.

Paterniani E and Campos MS (1999). Melhoramento do milho. In: Melhoramento de espécies cultivadas (Borém A, ed.). Universidade Federal de Viçosa, Viçosa, 429-486.

Röber FK, Gordillo GA and Geiger HH (2005). In vivo haploid induction in maize-performance of new inducers and significance of doubled haploid lines in hybrid breeding. Maydica 50: 275-283.

Rotarenco VA, Dicu G, State D and Fuia S (2010). New inducers of maternal haploids in maize. Maize Genetics Cooperation Newsletter, Urbana. Available at [http://www.agron.missouri.edu/mnl/84/PDF/15rotarenco.pdf]. Accessed January 22, 2013.

Shatskaya OA, Zabirova ER, Schcherbak VS and Chumak MV (1994). Mass induction of maternal haploids in corn. Maize Genet. Coop. News Lett. 68: 51.

Techio VH, Davide LC, Pedrozo CA and Pereira AV (2006). Viabilidade dos grãos de pólen de acessos de capim-elefante, milheto e híbridos interespecíficos (capim-elefante x milheto). Rev. Acta Sci. Biol. 28: 7-12. 